\title{
Creating large-scale maps for agriculture using remote sensing
}

\author{
Gayrat Yakubov ${ }^{1 *}$, Khamid Mubarakov ${ }^{1}$, Ilkhomjon Abdullaev ${ }^{1}$, and Azizjon Ruziyev ${ }^{1}$ \\ ${ }^{1}$ National University of Uzbekistan, Faculty of Geography and Natural Resources, Department of \\ Geodesy and Geoinformatics, 100174, Tashkent, Uzbekistan
}

\begin{abstract}
Reliable information on the real state of agricultural lands will be required to the development of appropriate measures for the rational use of agricultural lands. To obtain such information, it is necessary to keep permanent and systematic records and inventories of land resources. Largescale special plans and maps will be required for accounting, inventory and classification of agricultural land. Currently in Uzbekistan such cartographic materials are being created on the scale 1: 10000 and 1: 25 000 by administrative and territorial units, farms or individual land plots. The article considers the issues of creation of special maps of agricultural land in scale 1:10000 on the example of Sharof Rashidov district of Jizzakh region using remote sensing data with very high spatial resolution KOMPSAT-3.
\end{abstract}

\section{Introduction}

Agriculture is one of the most important sectors in the economy of the Republic of Uzbekistan. According to the latest data provided by The State Committee on Land Resources, Geodesy, Cartography and State Cadastre, $46.25 \%$ of the total territory of the country is used for agricultural purposes [1]. For rational, effective and targeted use, as well as for the protection of land resources, it is necessary to carry out accounting, analysis and evaluation by regularly and systematically obtaining information about their state. Largescale agricultural maps are important sources that provide the ability to quickly obtain information about the state of the land areas of specific administrative, territorial units. In order, cartographic, statistical data or results of terrestrial measurements and remote sensing materials are used to create agricultural maps [2]. However, remote sensing materials can be considered essential data in terms of their spatial, spectral and temporal resolution capabilities.

Nowadays, the data obtained from Earth Observing Systems such as Sentine-2, Landsat7, Landsat-8, EOS AM-1 can be used for agricultural purposes [3], they provide multispectral images with spatial resolutions from 10 meters to 250 meters. However, the images obtained from these spacecraft do not allow the creation of large-scale maps (1: 25000 and 1: 10000) of relatively small land plots (for example, farms) [4, 5]. Studies have shown the feasibility of using satellite images of very high spatial resolution $(\geq 0.5 \mathrm{~m})$ for

\footnotetext{
*Corresponding author: yakubov1203@gmail.com
} 
the creating and updating of large-scale maps, in terms of accuracy, reliability and efficiency $[6,7]$.

In recent years Uzbekistan has paid special attention to the introduction of modern technologies in agriculture. In particular, the Decree of the President of the Republic of Uzbekistan from May 31, 2017 (PU-5065) directed to the use of remote sensing materials for monitoring and mapping of land resources was adopted [8]. In addition, Presidential Decree No. PP-4709 was adopted on 11 May 2020 [9]. The Decree defines measures to specialise certain regions of the Republic of Uzbekistan, in particular the districts of Jizzak region, in the cultivation of agricultural products. Based on the above, the article deals with the issues of creation of large-scale (1: 10000) maps of agricultural land based on geographic information systems using global navigation satellite technology (GNSS) and remote sensing (RS) materials on the example of Sharof Rashidov district of Jizzakh region. (Figure 1).

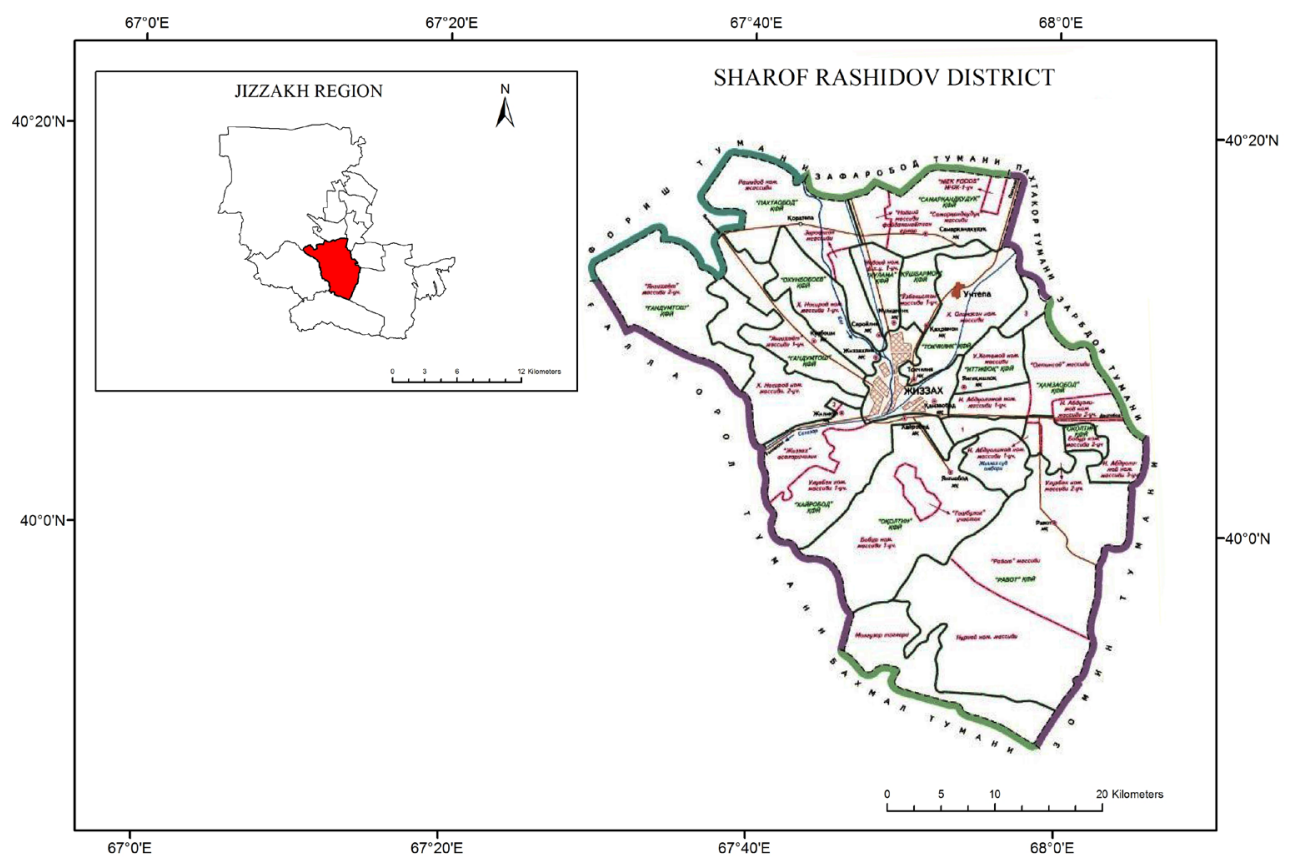

Fig. 1. Area of study - Jizzakh region, Sharof Rashidov district.

\section{Materials and methods}

The State Committee for Land Resources, Geodesy, Cartography and State Cadastre of the Republic of Uzbekistan is the main competent authority for the creation of cartographic products of various scales in the country. Currently, the Committee uses images with very high spatial resolution of the KOMPSAT (Korean Multi-Purpose Satellite) spacecraft for the rational, targeted use and protection of land resources. Currently, the KOMPSAT-3 spacecraft provides images over five spectral channels (panchromatic, blue, green, red and near infrared) with very high spatial resolution $(2.8 \mathrm{~m}$ in multispectral mode and $0.7 \mathrm{~m}$ in panchromatic mode).

Using satellite images of very high spatial resolution KOMPSAT-3, were created agricultural maps of 1: 10000 scale of Tashkent, Bukhara, Andijan, Ferghana and other regions by the State Unitary Enterprise Geoinformkadastr under the the Committee. 
To creation map of agricultural land users for the area of study, satellite images of KOMPSAT-3 with very high spatial resolution with an ortho-ready level were used. Orthophotoplan generation from the satellite images was performed in the following order:

- reconnaissance of the area of study and determination of the location of ground control points $(\mathrm{GCP})$;

- determine the coordinates of the GCP;

- photogrammetric processing of satellite images in a special software product.

To georeferencing satellite images, 6 triangulation points and 21 additionally defined control points were used (Figure 2). Geodetic measurements were performed with a Stonex S9 III PLUS GNSS receiver in RTK mode.

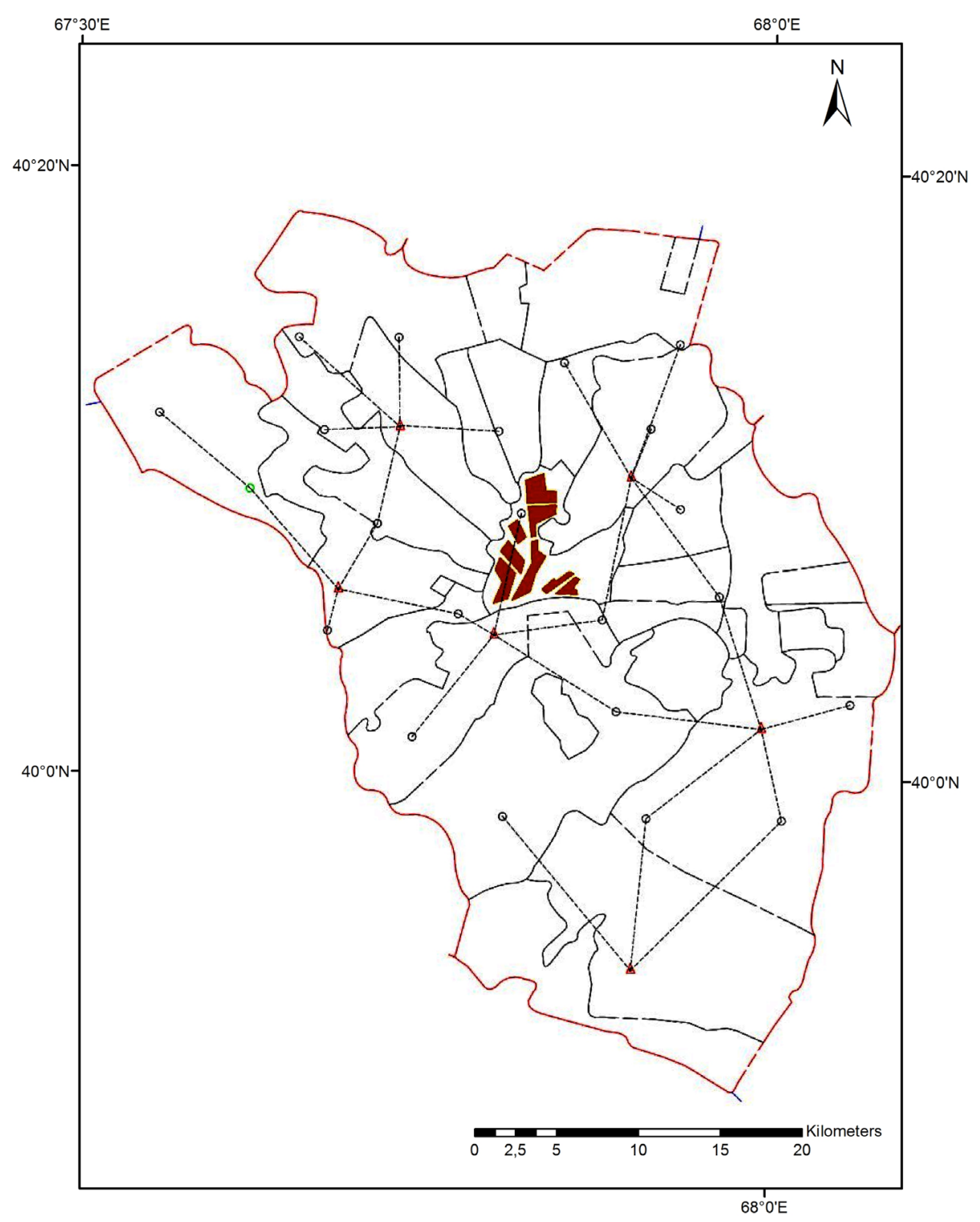

Fig. 2. Scheme of location of the GCP. 
The generation orthophotoplan using the coordinates of ground control points and the satellite images with the ortho-ready level was performed by the PHOTOMOD digital photogrammetric station in PhotoMOD Lite 6. 2 software package in the following order:

- determination of the location of control points in satellite images;

- photo triangulation;

- satellite image orientation;

- orthomosaic generation;

- orthophotoplan generation.

The last and complex step in creating the large scale map of the study area is the interpretation of satellite images. Interpretation of satellite images was carried out strictly in accordance with special instructions [10]. In the process of interpreting remote sensing materials, terrain objects were identified and marked with appropriate symbols. Interpretation or analysis of remote sensing data was carried out by visual method. At the same time, terrain objects, the reliability and correspondence of which are beyond doubt, were interpreted from space images using the Panorama 11 program of the Racurs company, and terrain objects that could not be identified by space objects were identified directly in the field. It should be noted that one of the most important objects of interpretation is the boundaries of land use and land ownership, settlements and lands of the state reserve. Boundaries, in terms of interpretation, refer to special objects.

\section{Results and discussions}

As a result of interpretations of satellite imagery, the location of agricultural lands, boundaries of land users, their areas and other natural and artificial objects was determined (Figure 3) and a map of land users in agriculture was created (Figure 4).

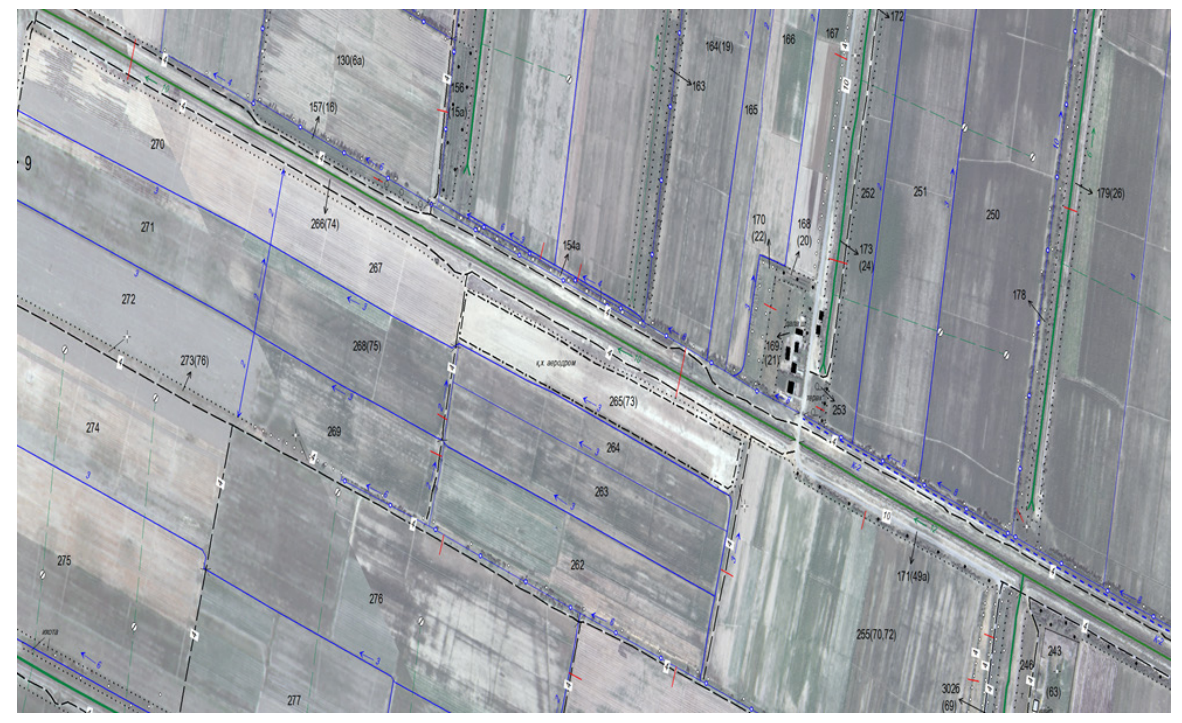

Fig 3. Fragment of the 1:10000 scale agricultural map. 


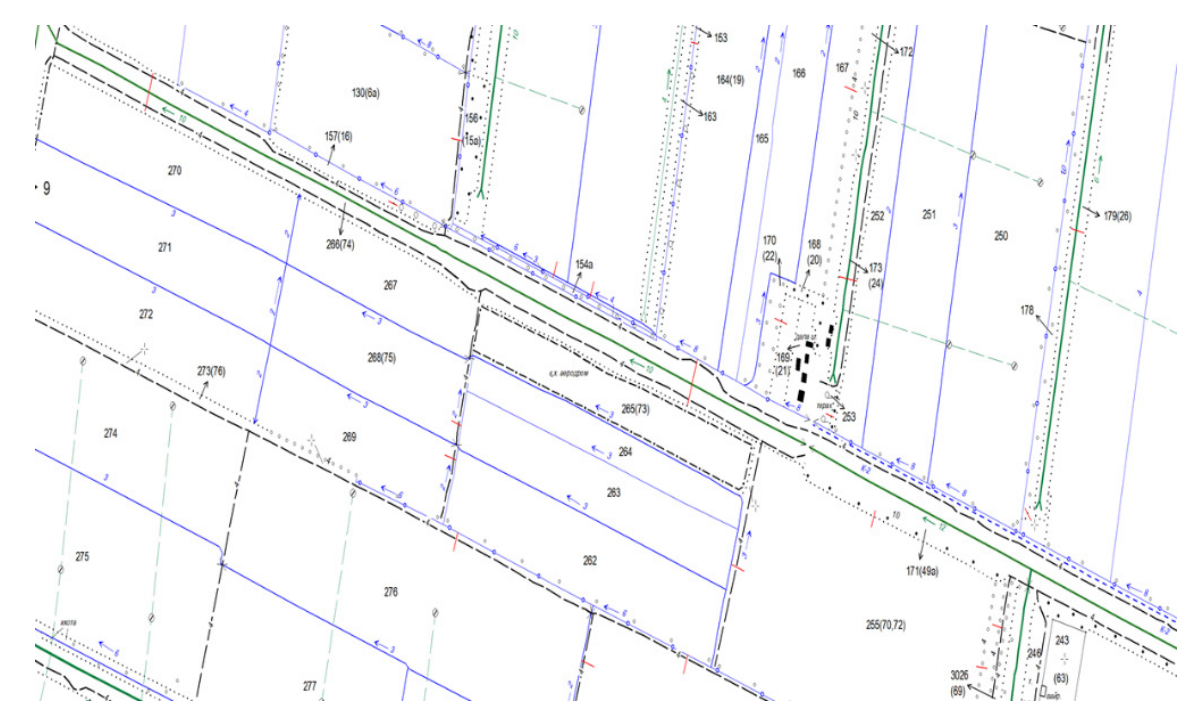

Fig 4. Fragment of the interprated orthophoto.

Such large-scale maps, which graphically represent information about the boundaries of land users and land uses (land tenure) and other real estate on land, as well as data on the actual use of land, are usually included in the group of cadastral maps and serve as the spatial basis for the formation of the cadastral database. They can serve to solve the following tasks:

- demonstration of natural features and the current state of land;

- displaying the structure of land holdings and their reclamation status;

- display of factors of negative anthropogenic, including technogenic, impact on the state of land;

- improving the accuracy of determining the boundaries and calculating the area of land;

- transition to new technologies and methods for studying and mapping lands;

- provision of detailed information in order to ensure the rational use and protection of land, the efficiency of land management [11].

Such maps serve as a topographic basis for creating maps of special content (soil, geobotanical, hydrogeological, underground communications, etc.).

\section{Conclusions}

The technology for creating land user maps in agriculture using very high-resolution satellite imagery was considered on the example of the study area - Sharof Rashidov district, Jizzakh region. Thanks to the use of ortho-ready satellite imagery of the KOMPSAT-3 spacecraft with a very high spatial resolution, it significantly reduced the time for photogrammetric processing, and the main attention was paid to the work on image interpretation. A large scale map of land users provides real information on the state of land used in agriculture, which subsequently serves as the basis for creation soil salinization maps, identifying factors affecting soil fertility, and developing important measures to address them. 


\section{References}

1. "National report on the state of land resources of the Republic of Uzbekistan", "Davyergeodezkadastr", Tashkent, Uzbekistan, (2019)

2. N. Stupen, M.Stupen, O.Stupen, "Electronic agricultural maps formation on the basis of GIS and earth remote sensing”, Sci. Pap. Ser. Man. Eco.Eng.Agr. Rur. Dev, vol. 18, no.4, pp. 347-352, (2018)

3. I.Rodin, "Analysis and preparation of RS data from open sources for precision farming systems”, Sci. Tech. J. Geod. Cartog. Nav "Geoprofi", Vol. 6, pp. 16-19, (2018)

4. V. Lebourgeois, S. Dupuy, É. Vintrou, M. Ameline, S. Butler and A. Bégué, “A Combined Random Forest and OBIA Classification Scheme for Mapping Smallholder Agriculture at Different Nomenclature Levels Using Multisource Data (Simulated Sentinel-2 Time Series, VHRS and DEM)”, Rem. Sen. Op. Acc. J, Vol. 9, no.3, pp. 120, (2017)

5. E. Bello, N. Chigbu, I. Agbaje, "Large scale mapping: an empirical comparison of pixel-based and object-based classifications of remotely sensed data”, South Afr. J. Geo, Vol. 6, no.3, pp. 277-294, (2017)

6. M. Gianinetto, "Updating Large Scale Topographic Databases in Italian Urban Areas with Submeter QuickBird Images”, Int. J. Nav. Obs. Vol. 2008, pp. 1-9, (2008)

7. W. Teijun, "The capability of IKONOS images for 1:10000 mapping informatsion China", Master Thesis, (2005)

8. Presidential Decree No. UP-5065 "On measures for strengthening control over protection and rational management of land, improvement of geodetic and cartographic activity, regulating keeping state cadastre and state registers", (Date of text: 31 May 2017)

9. Presidential Decree No. PP-4709 "On additional measures for specialization of the regions in the production of agricultural commodities", (Date of text: 11 May 2020)

10. (8) Instructions for interpretation aerial images and photoplans at scales of 1: 10,000 and 1: 25,000 for the purposes of land management, state land registration and land cadastre, (1978)

11. E. Pokhorova, "Socio-economic maps", (2018) 